Annales Geophysicae (2002) 20: 1479-1486 C) European Geophysical Society 2002

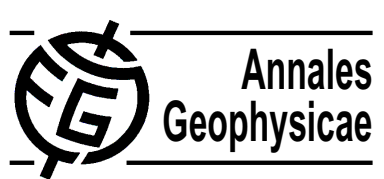

\title{
Doppler shift simulation of scattered HF signals during the Tromsø HF pumping experiment on 16 February 1996
}

\author{
T. D. Borisova ${ }^{1}$, N. F. Blagoveshchenskaya ${ }^{1}$, I. V. Moskvin ${ }^{1}$, M. T. Rietveld ${ }^{2}$, M. J. Kosch ${ }^{3}$, and B. Thidé ${ }^{4}$ \\ ${ }^{1}$ Arctic and Antarctic Research Institute, 38, Bering Str., St. Petersburg, 199397, Russia \\ ${ }^{2}$ Max-Plank-Institut für Aeronomie, D-37191, Katlenburg-Lindau, Germany \\ ${ }^{3}$ Dept. Communication Systems, Lancaster University, LA1 4YR, Lancaster, UK \\ ${ }^{4}$ Swedish Institute of Space Physics, Uppsala Division, Box 537, SE 75121 Uppsala, Sweden
}

Received: 16 October 2001 - Revised: 21 March 2002 - Accepted: 26 March 2002

\begin{abstract}
Comparisons between bistatic scatter measurements and simulation results during the Troms $\varnothing$ HF pumping experiment on 16 February 1996 are made. Doppler measurements of an HF diagnostic signal scattered from the fieldaligned irregularities (FAIs) in the auroral E-region were carried out on the London - Troms $\varnothing$ - St. Petersburg path at $9410 \mathrm{kHz}$ from 21:00 to 22:00 UT. The scattered signals were observed both from natural and artificial ionospheric irregularities located in the vicinity of Tromsø. To simulate the Doppler frequency shifts, $f_{d}$, of scattered signals, a radio channel model, named CONE, was developed. The model allows for ray tracing, group and phase paths, and Doppler frequency shift calculations. The calculated Doppler shifts were analyzed for dependence on the magnitude and direction of plasma velocities in the scattering volume. It was found that the velocity components in the north-south direction are crucial for explaining the Doppler frequency shifts of the scattered diagnostic signals. To simulate $f_{d}$, real velocities obtained from the EISCAT UHF radar at an altitude of $278 \mathrm{~km}$ and from the digital all-sky imager during the experiment were employed. The simulation results of Doppler frequency shift variations with time are in reasonable agreement with the experimental Doppler shifts of scattered signals on the London - Troms $\varnothing$ - St. Petersburg path.
\end{abstract}

Key words. Ionosphere (active experiments; ionospheric irregularities) Radio science (ionospheric propagation)

\section{Introduction}

Modification experiments in which the nightside auroral ionosphere is irradiated by powerful HF radio waves have revealed a multitude of nonlinear phenomena caused by the interaction of the HF pump wave and ionospheric plasma (Djuth et al., 1985; Noble et al., 1987; Blagoveshchenskaya et al., 1998a, 1999, 2001; Brandström et al., 1999). One

Correspondence to: N. F. Blagoveshchenskaya

(nataly@aari.nw.ru) of the prominent phenomena from HF modification experiments is the generation of artificial field-aligned irregularities (AFAIs) with scale sizes of the order of a few meters across the magnetic field lines. At high-latitudes AFAIs can be excited not only in the F-region, but in the auroral E-region as well. Recent studies of these heater-induced irregularities in the F2-layer of the ionosphere showed that their motion was consistent with the background plasma drift (Eglitis et al., 1998).

In an earlier publication, Blagoveshchenskaya et al. (2001) examined the experimental results from Troms $\varnothing$ HF pumping experiments in the nightside auroral E-region. Bistatic scatter measurements were carried out on the London - Troms $\varnothing$ - St. Petersburg path using the Doppler spectral method from St. Petersburg at a distance of about $1200 \mathrm{~km}$ from Tromsø. It was shown that the scattered signals were observed both from natural and artificial ionospheric irregularities during the HF pumping experiment on 16 February 1996.

The present paper concentrates on the simulation of diagnostic HF scattered signals on the London - Troms $\varnothing-$ St. Petersburg path during the Troms $\varnothing$ HF pumping experiment on 16 February 1996. The goal is to compare the simulated and observed Doppler frequency shifts $f_{d}$ of the diagnostic HF signals scattered from field-aligned small-scale irregularities. To simulate $f_{d}$, plasma velocities in the scattering volume obtained from EISCAT UHF radar (Rishbeth and van Eyken, 1993) measurements, as well as from digital all-sky imager (DASI) (Kosch et al., 1998) observations were employed. DASI is located at Skibotn, about $50 \mathrm{~km}$ from the EISCAT HF pump facility.

\section{Observational results}

Bistatic scatter measurements of HF diagnostic signals were carried out on the London - Troms $\varnothing$ - St. Petersburg path at $9410 \mathrm{kHz}$. Ionospheric modification was produced by the EISCAT HF heating facility (Rietveld et al., 1993) located near Troms $\varnothing$ (geographical coordinates $69.6^{\circ} \mathrm{N}, 19.2^{\circ} \mathrm{E}$, 

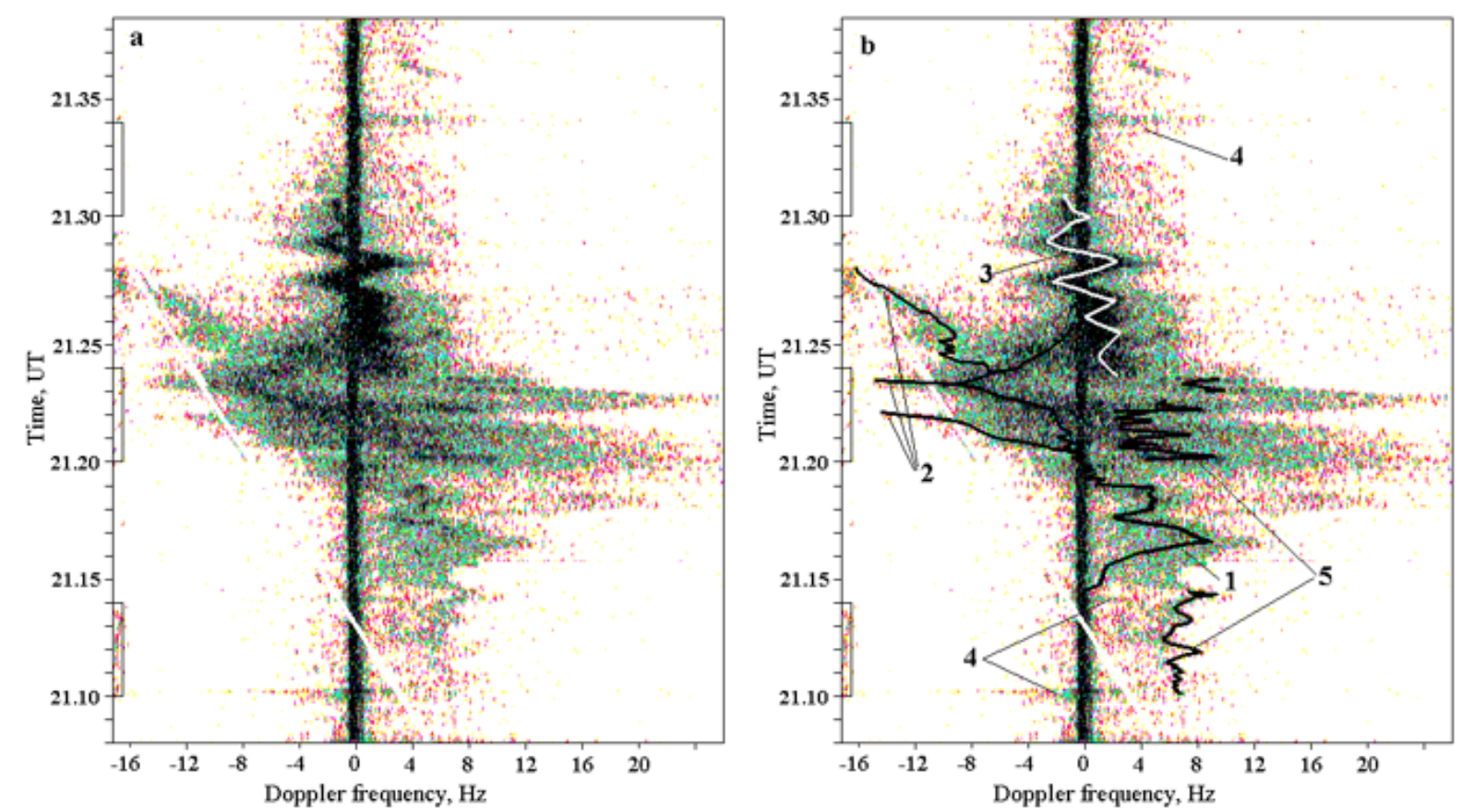

Fig. 1. Dynamic Doppler spectra (sonogram) of HF diagnostic signals on the London - Troms $\varnothing-$ St. Petersburg path at $9410 \mathrm{kHz}$ during the Troms $\varnothing$ HF pumping experiment on 16 February 1996. Direct signal propagating from the transmitter to the receiver along a great circle path corresponds to $0 \mathrm{~Hz}$ Doppler frequency. The intervals when the Troms heater was turned on are marked by bars on the time axis: (a) raw dynamic Doppler spectra; (b) dynamic Doppler spectra with five types of Doppler tracks displayed on the sonogram. The following Doppler tracks can be recognized from the sonogram: (1) the long-lived track from 21:10 to 21:26 UT with Doppler frequency shifts changing from positive to negative values; (2) the negative tracks of 21:20-21:22 UT, 21:22-21:23 UT and 21:24-21:28 UT with increasing negative values of Doppler frequency shift; (3) the wave-like track with periods of about 100-120 s observed from 21:23:30 to 21:30:30 UT; (4) burst-like Doppler tracks closely related to the points in time at which the Troms $\varnothing$ HF heating facility is turned on or off; (5) wave-like tracks closely related to the heater-on periods of 21:10-21:14 and 21:20-21:24 UT.

$L=6.2$, magnetic dip angle $I=78^{\circ}$ ). The experiment was conducted on 16 February 1996 from 21:00 to 23:00 UT. The main parameters of the Troms $\varnothing$ heater were the following: heater frequency $=4040 \mathrm{kHz}$; polarization $=$ O-mode; effective radiated power $(\mathrm{ERP})=150 \mathrm{MW}$; transmission scheme $=4 \mathrm{~min}$ on $/ 6 \mathrm{~min}$ off. The antenna beam was tilted $6^{\circ}$ to the south, allowing for HF pumping in a near field-aligned direction. The diagnostic HF transmitter is located near London $\left(52^{\circ} \mathrm{N}, 0^{\circ} \mathrm{E}\right)$. The reception of diagnostic waves, scattered from field-aligned irregularities (FAIs) above Troms $\varnothing$, was made using the Doppler spectral method from St. Petersburg $\left(60^{\circ} \mathrm{N}, 30.5^{\circ} \mathrm{E}\right)$.

During the experiment the Troms $\emptyset$ dynasonde showed the presence of a sporadic $E_{S}$ layer. However, $f_{o} E_{s}$ remained less than the heater frequency $f_{H}$ during the first two heateron periods (21:00-21:04 UT and 21:10-21:14 UT). Hence, the pump wave was not reflected from $E_{s}$ layer. Since the electron density was low in the F2-layer as well, the HF pump wave was not reflected from the ionosphere at all. In the following, heater-on periods $f_{o} E_{S}$ exceeded $f_{H}$, resulting in reflection of the powerful HF radio wave from the sporadic $E_{s}$ layer.

Figure 1 shows the dynamic Doppler spectra on the Lon- don - Troms $\varnothing$ - St. Petersburg path obtained on 16 February 1996 from 21:08 to 21:40 UT. Figure 1a shows the raw dynamic Doppler spectra. The spectral structure of the HF signals scattered from FAIs is quite complicated. However, analysis of the dynamic Doppler spectra allows for five different types of Doppler tracks to be identified, as shown in Fig. 1b.

The first type of track (track 1) was observed continuously from 21:15 to 21:26 UT, irrespective of whether the HF heater was turned on or off. The distinctive feature of this track is the change in sign of the Doppler frequency shifts $f_{d}$ from positive to negative, that takes place at 21:20 UT. Upon reaching the maximum negative value of $f_{d}$ at 21:23 UT, track 1 turns back towards a zero Doppler frequency shift.

Tracks 2 are negative with increasing negative values of Doppler frequency shift from 21:20-21:22 UT, 21:2221:23 UT, and 21:24-21:28 UT.

A very intense wave-like track (track 3 ) with a period of about 100-120 s appeared at 21:23:30 UT at the end of the heater-on period of 21:20-21:24 UT. Its duration was about $7 \mathrm{~min}$. It was found that variations of Doppler frequency shift with time are in a good agreement with electron density changes over Troms $\emptyset$. A comparison between $f_{d}$ 


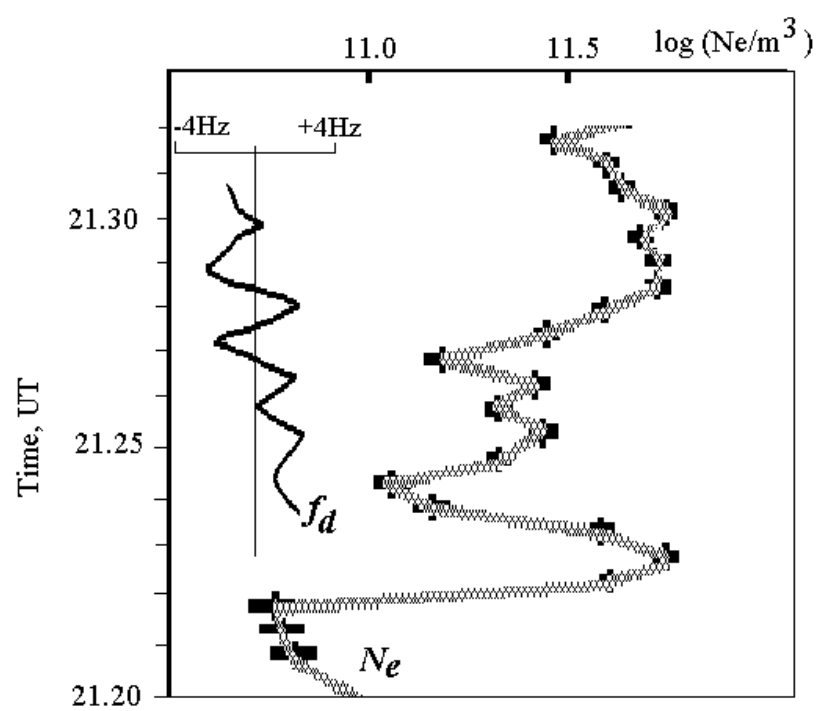

Fig. 2. Temporal variations of electron density $N_{e}$ at $150 \mathrm{~km}$ altitude from Troms $\varnothing$ EISCAT UHF radar measurements and Doppler frequency variations $f_{d}$ characterizing track 3 on 16 February 1996.

variations characterizing track 3 and $N_{e}$ changes at an altitude of $150 \mathrm{~km}$ from EISCAT UHF radar measurements at Troms $\varnothing$ is shown in Fig. 2.

An interesting feature of the HF pumping experiment on 16 February 1996 is exhibited by the fourth type of track (track 4). These burst-like tracks are closely related to the point in time at which the Troms $\varnothing$ heater is turned on and off. The duration of the burst-like tracks is about $10-15 \mathrm{~s}$. When turning on the Troms $\varnothing$ HF heater, a burst in $f_{d}$ to $-10 \mathrm{~Hz}$ occurs in the negative part of the Doppler sonogram. HF heater turn off leads to the appearance of a $f_{d}$ burst to $+8 \mathrm{~Hz}$ in the positive part of sonogram. The most pronounced burst-like tracks were observed in the heater-on periods of 21:10-21:14 UT and 21:30-21:34 UT. It is interesting to note that similar negative burst-like Doppler tracks were observed from bistatic scatter measurements when turning on the SURA heating facility (see Fig. 6 of Blagoveshchenskaya et al., 1998b).

During the pump cycle of 21:10-21:14 UT the powerful $\mathrm{HF}$ radio wave was not reflected from the ionosphere due to $f_{H}$ exceeding $f_{o} E_{S}\left(f_{H}>f_{o} E_{S}\right)$. In addition, the heater frequency $f_{H}$ was equal to the upper hybrid frequency $f_{U H}$, i.e. $f_{H}^{2}=f_{U H}^{2}=f_{o}^{2} E_{s}+f_{c}^{2}$, where $f_{o} E_{s}$ is the maximum frequency of the sporadic $E_{s}$ layer and $f_{c}$ is the cyclotron frequency. Note that the excitation of artificial field-aligned irregularities in the auroral $E_{S}$ layer is possible with the constraint $f_{H}>f_{o} E_{s}$, but $f_{H}^{2}=f_{o}^{2} E_{s}+f_{c}^{2}$, as described by Djuth et al. (1985).

The fifth type of track is closely related to the heater-on periods of 21:10-21:14 UT and 21:20-21:24 UT. These wavelike tracks, with periods of about $80-120 \mathrm{~s}$, are displayed in the positive part of the Doppler sonogram. During the HF pumping cycle of 21:10-21:14 UT the appearance and disappearance of the fifth type of track coincides in time with the burst-like heater-induced tracks of the fourth type. As a result, it is believed that this track was produced by HF diagnostic signals scattered from artificial field-aligned irregularities.

It is of interest to compare the observed wavy tracks with the behaviour of the $X$ and $Y$ components of the magnetic field variations at Troms $\varnothing$. In order to do this, the spectral components of $f_{d}, X$ and $Y$ were computed. The comparison showed an absence of correlation between the Doppler frequency shift variations and magnetic field variations.

The Doppler tracks shown in Fig. 1b suggest that the scattered signals were observed both from natural (first, second and third types) and artificial (the fourth and fifth types) fieldaligned irregularities.

\section{Modelling}

The problem of HF radio-wave propagation in an inhomogeneous anisotropic (magnetoactive) ionosphere was solved within the framework of the geometric optics method. In this context, the solution of the wave equation and determination of the ray path is an Eikonal function solution. The solution of the Eikonal function is equivalent to finding the dependence of $\omega=\omega(\boldsymbol{k})$, where $\omega$ is the wave (angular) frequency $(\omega=2 \pi f)$, and $\boldsymbol{k}$ is the wave vector. Taking into account the canonical equations for a ray (Budden, 1985) and the Eikonal function (Kravtzov, 1980), the following system of differential equations for an inhomogeneous anisotropic medium are derived:

$$
\begin{aligned}
\frac{d \boldsymbol{r}}{d t} & =2 c^{2}\left(\boldsymbol{k}-\frac{1}{2} \frac{\omega^{2} \partial n^{2}}{c^{2} \partial \boldsymbol{k}}\right) / \frac{\partial \omega^{2} n^{2}}{\partial \omega} \\
\frac{d \boldsymbol{k}}{d t} & =\omega \frac{\partial n}{\partial \boldsymbol{r}} / \frac{\partial \omega n}{\partial \omega} \\
\frac{d \omega}{d t} & =-\omega \frac{\partial n}{\partial t} / \frac{\partial \omega n}{\partial \omega} .
\end{aligned}
$$

The refractive index may be written as (Ginzburg, 1967)

$n_{1,2}^{2}=1-$

$\frac{2 v(1-v)}{2(1-v)-u \sin ^{2} \alpha \pm \sqrt{u^{2} \sin ^{4} \alpha+4 u(1-v)^{2} \cos ^{2} \alpha}}$,

where $u$ and $v$ are determined by

$v=\frac{\omega_{0}^{2}}{\omega^{2}}=\frac{4 \pi e^{2} N_{e}}{m \omega^{2}}$,
$\sqrt{u}=\frac{\omega_{H}}{\omega}=\frac{|e| H^{0}}{m c \omega}$.

Here $e$ and $m$ are the electron charge and mass; $c$ is the speed of light; $\alpha$ is the angle between the wave vector $\boldsymbol{k}$ and magnetic field $H^{(0)}, \omega_{0}$ is the electron plasma frequency, and $\omega_{H}$ is the electron gyrofrequency.

On the basis of the equation system (1) and taking into account expression (2) for the refractive index, a radio channel model, named CONE, was developed. It permits the ray 


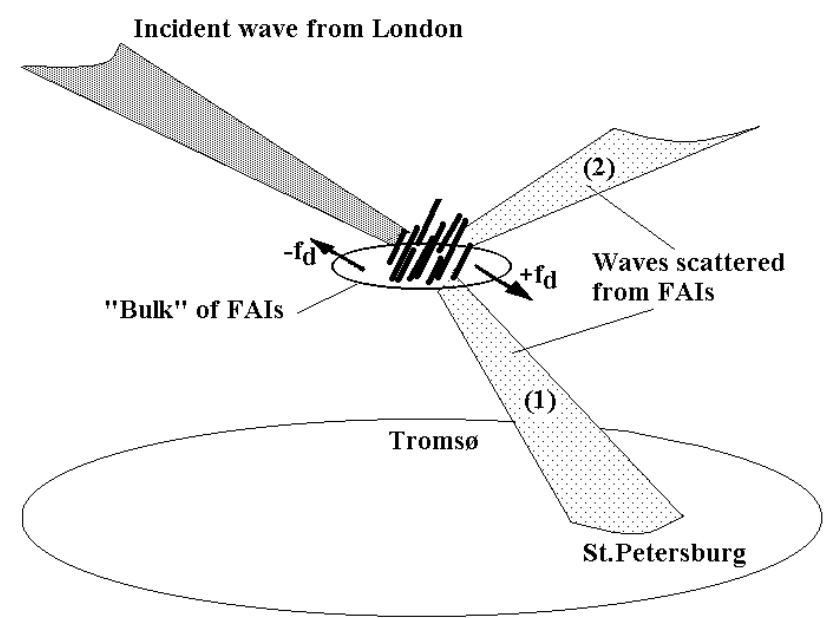

Fig. 3. Sketch of the geometry of the scattered signals from moving field-aligned irregularities. Digits (1) and (2) correspond to the different modes of the signals scattered from FAIs above Troms. Signs "+" and "_" in Doppler frequency shift are in accordance with the movements of FAIs in the direction of the receiver $\left(+f_{d}\right)$ and from the receiver $\left(-f_{d}\right)$.

traces, as well as the group and phase paths to be calculated. The numerical solution of equation system (1) is performed in the standard way (Haslegrove, 1955) as the solution of the differential equations of radio-wave propagation in a magnetoactive plasma using Runge-Kutta methods in spherical coordinates.

The propagation direction of the HF diagnostic wave on the London - Troms $\varnothing-$ St. Petersburg path is given by two great circle paths as follows: the first path is from the diagnostic transmitter (London) to the scattering volume above Troms $\varnothing$ and the second one is from the scattering volume to the receiver (St. Petersburg). The boundary condition for linking the solutions for the two propagation paths is the FAIinduced scattering cone, given by

$\left(\boldsymbol{k}_{o} \cdot \boldsymbol{H}\right)=\left(\boldsymbol{k}_{s} \cdot \boldsymbol{H}\right)$,

where $\boldsymbol{k}_{o}$ and $\boldsymbol{k}_{s}$ are the wave vectors of the incident and scattered wave, correspondingly, and $\boldsymbol{H}$ is the vector of the Earth's magnetic field. The simulation of the geometry of the diagnostic HF signals scattered from FAIs in the auroral E-region on the London - Troms $\varnothing$ - St. Petersburg path was considered by Blagoveshchenskaya et al. (1999).

The CONE program also calculates the Doppler shift of scattered signals. To do this, we have taken into account not only the spatial-temporal electron density changes, but also the movements of the ionospheric plasma in the scattering volume. The latter is simply solved by the use of the locality principle for the phases $(\phi)$ on the moving boundary $A$ (Kravtzov, 1980), written as

$\left.\phi_{\text {inc }}\right|_{A}=\left.\phi_{\text {scat }}\right|_{A}$.

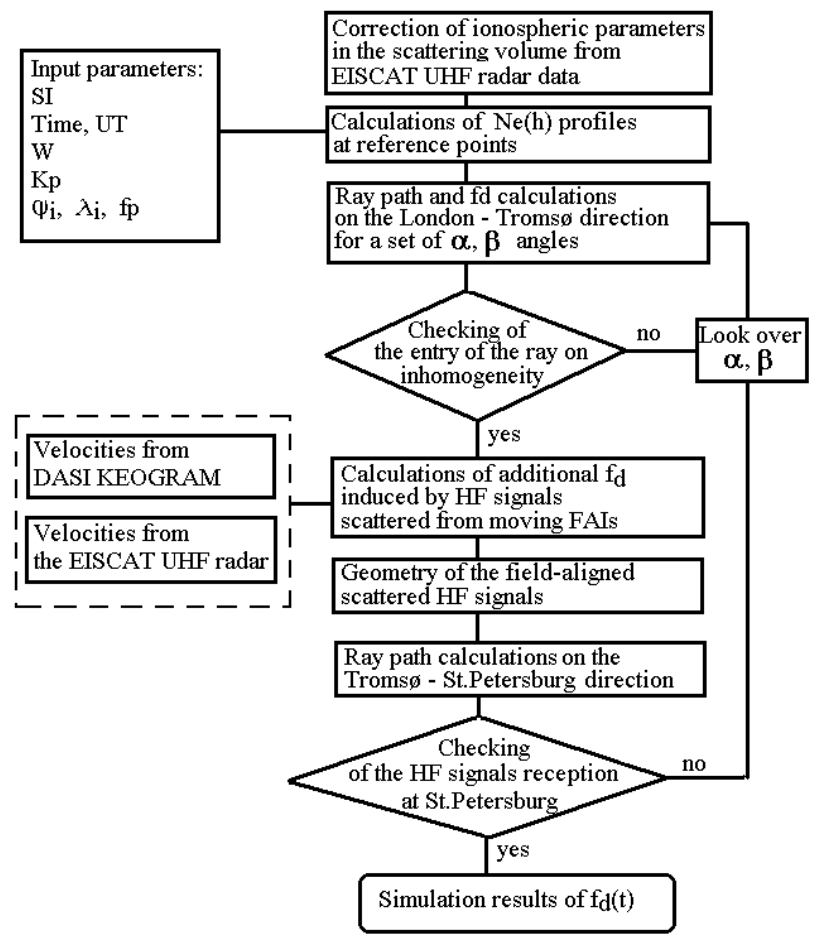

Fig. 4. Schematic of the algorithm of the CONE radio channel model.The following designations are used: $S I$ - solar declination (day number of year); $W$ - Wolf number; $K_{p}$ - planetary index of magnetic activity; $\phi_{i}, \lambda_{i}$ - geographical coordinates of transmitter, receiver and the scattering region; $f_{p}$ - operational frequency; $f_{d}$ Doppler frequency shift; $\alpha, \beta$ - angles of the radiation in the vertical (elevation) and horizontal (azimuth) plane, respectively; FAIs field-aligned irregularities.

Differentiating Eq. (4) in time, one obtains the following relation

$-\omega_{\text {inc }}+\left(\boldsymbol{k}_{o} \cdot \boldsymbol{V}\right)=-\omega_{\text {scat }}+\left(\boldsymbol{k}_{s} \cdot \boldsymbol{V}\right)$,

where $\boldsymbol{V}$ is the velocity of irregularities.

Figure 3 shows a sketch of the geometry of HF diagnostic signals scattered from moving FAIs. Bulk movement of the FAIs in the direction of the receiver (St. Petersburg) leads to a positive $f_{d}$ in the HF diagnostic signals scattered from these FAIs. When the FAIs are moving in a direction opposite to the receiver, the scattered signals have negative values of Doppler frequency shift $\left(-f_{d}\right)$. Figure 4 presents the scheme of the CONE radio channel model algorithm.

A global ionospheric model was used in the calculations, combining well-known models of the E-, F1- and F2-layers (Anufrieva and Shapiro, 1976; Chernyshov and Vasil'eva, 1975; Bilitza et al., 1992). The input parameter to the ionospheric model is an effective analog of the Wolf number $W_{\text {eff }}$, which takes into account not only the solar activity, but the magnetic activity as well (Blagoveshchensky and Borisova, 1989). The ionospheric model was corrected using real ionospheric data obtained from the EISCAT UHF radar at Troms $\varnothing$ and vertical ionospheric sounders located at Kiruna $\left(67.8^{\circ} \mathrm{N}\right.$; 


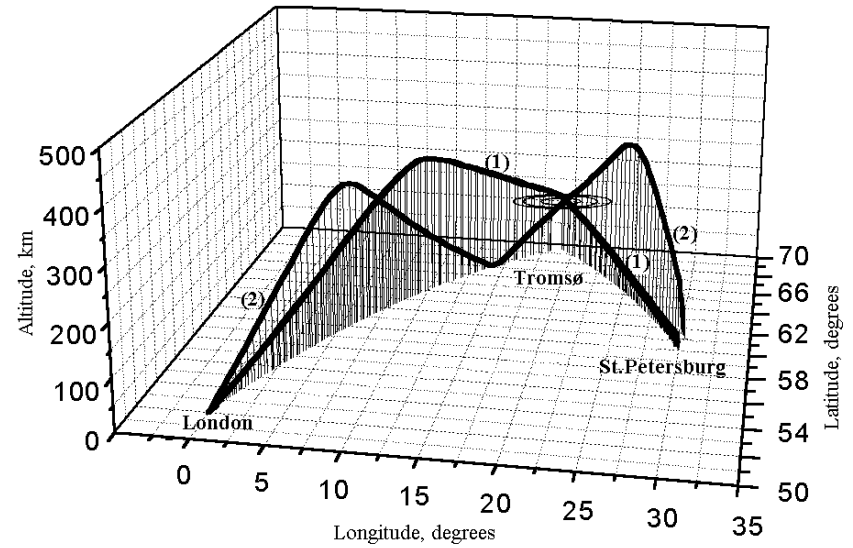

Fig. 5. Three-dimensional view of the simulation of the geometry of diagnostic HF signals scattered from E-region field-aligned irregularities on the London - Troms $\varnothing$ - St. Petersburg path at $9410 \mathrm{kHz}$ for the geophysical conditions on 16 February 1996 at 21:20 UT. (1) and (2) indicate the different propagation modes from London to Troms $\varnothing$ and from Troms $\varnothing$ to St. Petersburg.

$\left.20.4^{\circ} \mathrm{E}\right)$, Lerwick $\left(60.1^{\circ} \mathrm{N} ; 2^{\circ} \mathrm{W}\right)$, and St. Petersburg $\left(60^{\circ} \mathrm{N}\right.$; $\left.30.5^{\circ} \mathrm{E}\right)$.

Ionospheric parameters are taken from reference points within a geographical region bounded by latitudes 50 and $75^{\circ} \mathrm{N}$ and longitudes 5 and $35^{\circ} \mathrm{E}$. The spatial resolution is 2 degrees in latitude and longitude and $5 \mathrm{~km}$ in altitude throughout the ionosphere. The electron density for any coordinates is found using third order spline-functions. The solution for two-point HF propagation on the London - Troms $\varnothing$ path was found by testing exhaustively all elevation and azimuth angles with a resolution of $0.01-0.05^{\circ}$ and $0.1-0.5^{\circ}$, respectively.

Figure 5 displays an example of the simulation of the ray geometry of diagnostic HF radio-waves scattered from fieldaligned irregularities in the auroral E-region on the LondonTroms $\varnothing$ - St.Petersburg path at $9410 \mathrm{kHz}$ for the geophysical conditions on 16 February 1996 at 21:20 UT ( $W_{\text {eff }}=80$ ). From Fig. 5 one can see two modes of radio-wave propagation from London to Troms $\varnothing$. The first one corresponds to one-hop propagation when a diagnostic wave is incident on the scattering volume over Troms $\emptyset$ from above. The second one is for the radio wave, which comes to the scattering volume from below after reflection from the F2-layer and Earth's surface. Propagation of the scattered waves from Troms $\varnothing$ to St. Petersburg is also possible on two paths. One of them is direct propagation and the other one is propagation after reflection from the ionospheric F2-layer.

Using the CONE model, calculations of the Doppler frequency shifts of scattered signals on the London - Troms $\varnothing$ - St. Petersburg path were performed depending on the direction of the plasma velocities in the scattering volume for different magnitudes of velocity. These results are shown in Fig. 6. It is found that the velocity components in the north-south direction are crucial in determining the Doppler frequency shift values of the scattered signals (see Fig. 6).

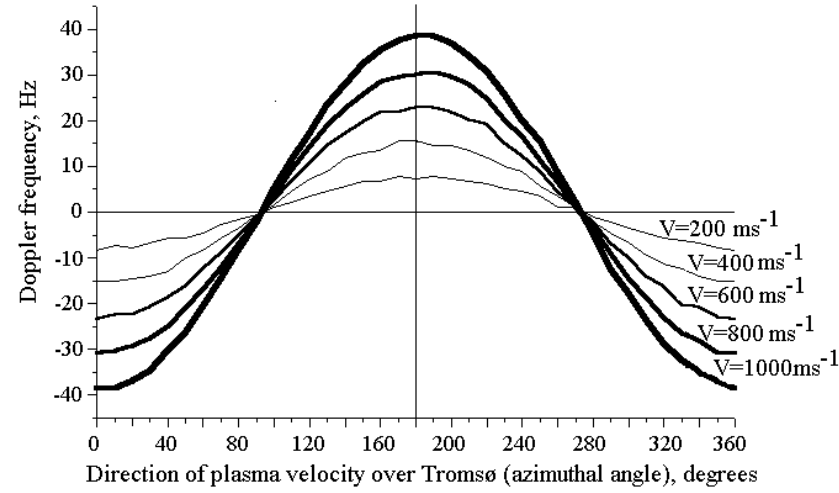

Fig. 6. Calculated values of Doppler frequency shift $f_{d}$ versus direction of plasma velocity for velocities in the range from 200 to $1000 \mathrm{~m} / \mathrm{s}$ on the London - Troms $\varnothing$ - St. Petersburg path. Calculations are made for $9410 \mathrm{kHz}$ and an electron density in the scattering volume in the auroral E-region corresponding to $f_{0} E_{S}=4700 \mathrm{kHz}$.

\section{Simulation results with moving FAIs}

To simulate the Doppler frequency shifts of diagnostic HF signals scattered from FAIs in the vicinity of Troms $\varnothing$ during the experiment on 16 February 1996, real ionospheric movement data were employed. Velocities obtained from EISCAT UHF radar measurements and from the digital all-sky imager (DASI) at Skibotn have been used.

\subsection{Velocities from EISCAT UHF radar observations}

The ionospheric plasma velocities from the EISCAT UHF radar were observed at an altitude of $278 \mathrm{~km}$ with 2-min temporal resolution. It is assumed that the coupling between the F- and E-regions through the magnetic field lines is perfect, on average (Hanuise et al., 1986). Hence, plasma velocities obtained in the F-region may be employed in the E-region of the ionosphere. Figure 7 illustrates the simulation results of Doppler frequency shifts on the London Troms $\varnothing-$ St. Petersburg path for the geophysical conditions corresponding to the experiment on 16 February 1996. The plasma velocity vectors, from EISCAT UHF radar measurements on 16 February 1996, between 21:08 and 21:36 UT, are shown in Fig. 7a. The calculated Doppler frequency shift values between 21:08 and 21:36 UT, taking into account only electron density changes in the scattering volume with 2-min temporal resolution, are shown in Fig. 7b. Figure 7c presents the calculated Doppler frequency shifts of the diagnostic HF signals scattered from FAIs in the auroral E-region, taking into consideration plasma velocities from the EISCAT UHF radar, as well as electron density changes in the scattering volume. 

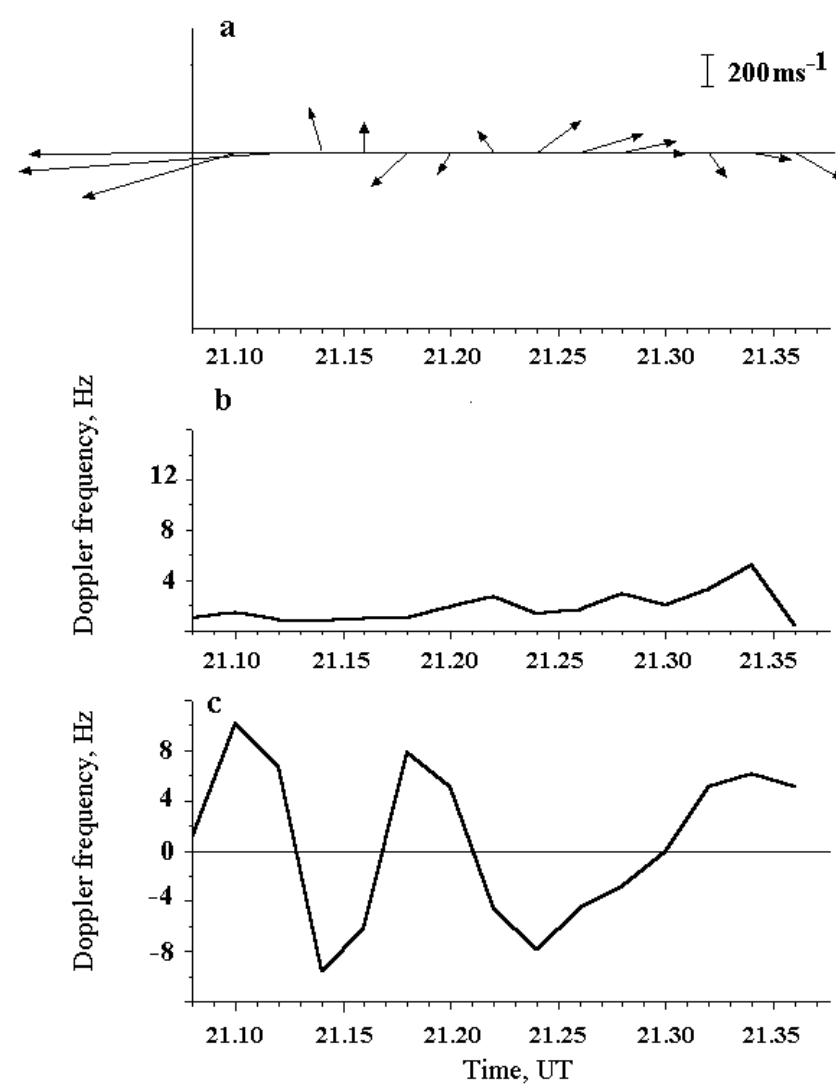

Fig. 7. Simulation results of Doppler frequency shifts on the London - Troms $\varnothing$ - St. Petersburg path at $9410 \mathrm{kHz}$ for the geophysical conditions on 16 February 1996, taking into account the real ionospheric data from EISCAT UHF radar measurements with 2min temporal resolution: (a) plasma velocity vectors from EISCAT UHF radar measurements during the HF pumping experiment on 16 February 1996; (b) Doppler frequency shifts versus time, taking into account only electron density changes in the scattering volume; (c) Doppler frequency shifts versus time, taking into account the plasma velocities given in panel " $a$ ", as well as electron density changes in the scattering volume.

\subsection{Velocities from optical measurements}

It can be assumed that the movement of FAIs in the scattering volume at auroral E-region altitudes above Troms $\varnothing$ is consistent with the movement of the visible aurora. Based on this assumption, a method was developed for finding velocities from optical data which were then used to calculate the Doppler frequency shifts of HF diagnostic signals scattered from FAIs on the London - Troms $\varnothing$ - St. Petersburg path. Simulation results of Doppler frequency shifts (see Fig. 6) have shown that the north-south component of the FAI velocities is crucial for bistatic HF scatter measurements on the London - Troms $\varnothing$ - St. Petersburg path. It is possible to find the north-south component of the FAI velocities from auroral optical data based on DASI keogram data (latitude-time plot) shown in Fig. 8a, which shows the luminosity intensity at a fixed longitude $\left(19.25^{\circ} \mathrm{E}\right)$ using geographic latitude-time
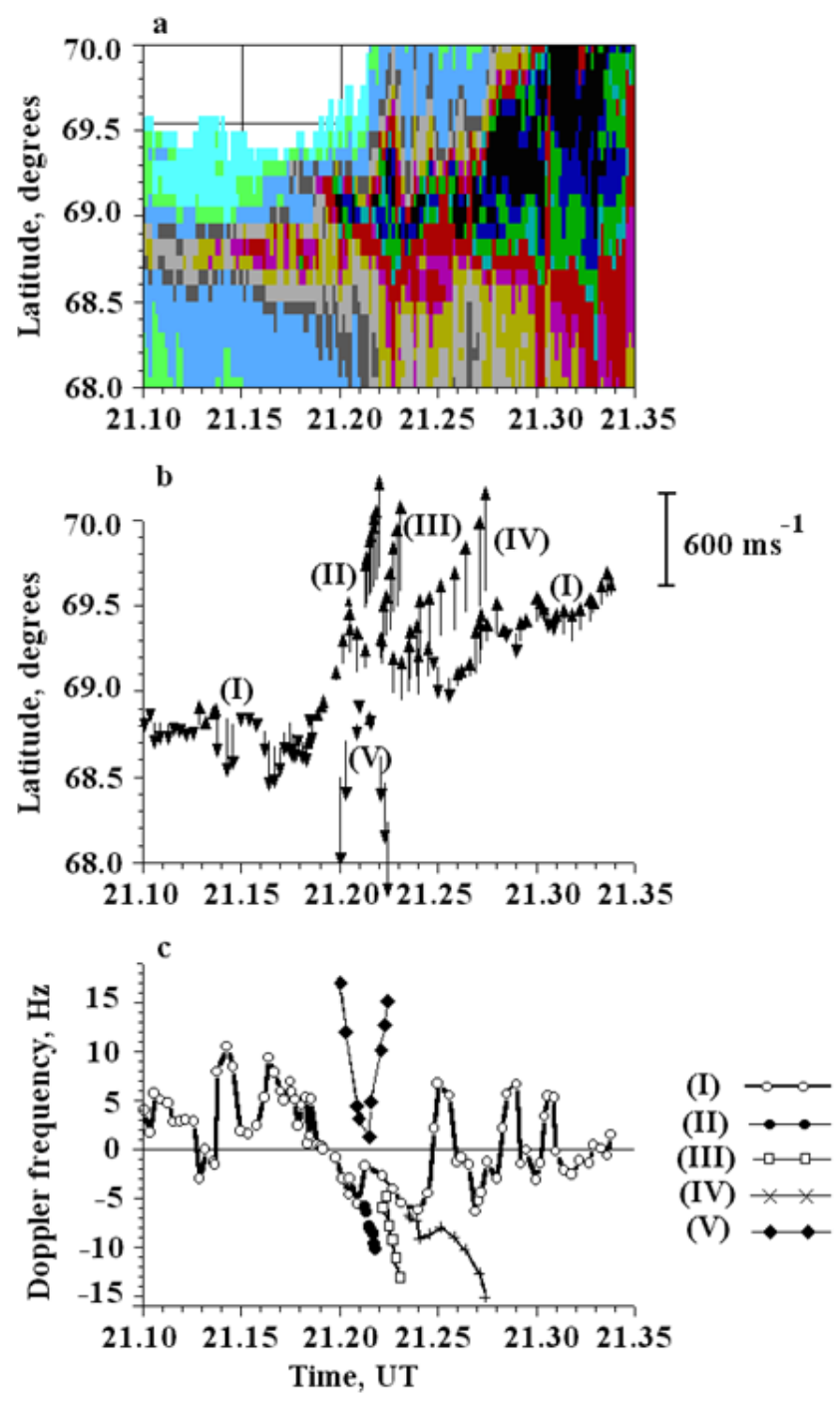

Fig. 8. Simulation results of Doppler frequency shifts on the London - Troms $\varnothing$ - St. Petersburg path at $9410 \mathrm{kHz}$ for the geophysical conditions on 16 February 1996, taking into account the velocity of auroral arc movements on the longitude of Troms $\varnothing\left(19.25^{\circ} \mathrm{E}\right)$ from the DASI keogram: (a) the DASI keogram; (b) velocities from the DASI keogram; (c) Doppler frequency shifts versus time, taking into account the velocities of auroral arcs shown in panel "b", as well as electron density changes in the scattering volume from EISCAT UHF radar measurements shown in Fig. 2.

coordinates and $10 \mathrm{~s}$ resolution data. Initially, smoothed isolines of equal luminosity were determined. Then the velocity was calculated as a time derivative $\Delta y / \Delta t$, where $\Delta y$ is the change of latitude (in $\mathrm{km}$ ) for the same isoline. Figure $8 \mathrm{~b}$ presents the north-south component of velocities obtained from the DASI keogram. The velocities obtained were included in the calculation of Doppler frequency shift $f_{d}$ on the London - Troms $\varnothing$ - St. Petersburg path, which are shown in Fig. 8c. There are five Doppler tracks corresponding to five different auroral movements in the DASI keogram during the experiment on 16 February 1996 between 21:10 and 21:35 UT. Velocities obtained from the DASI keogram char- 


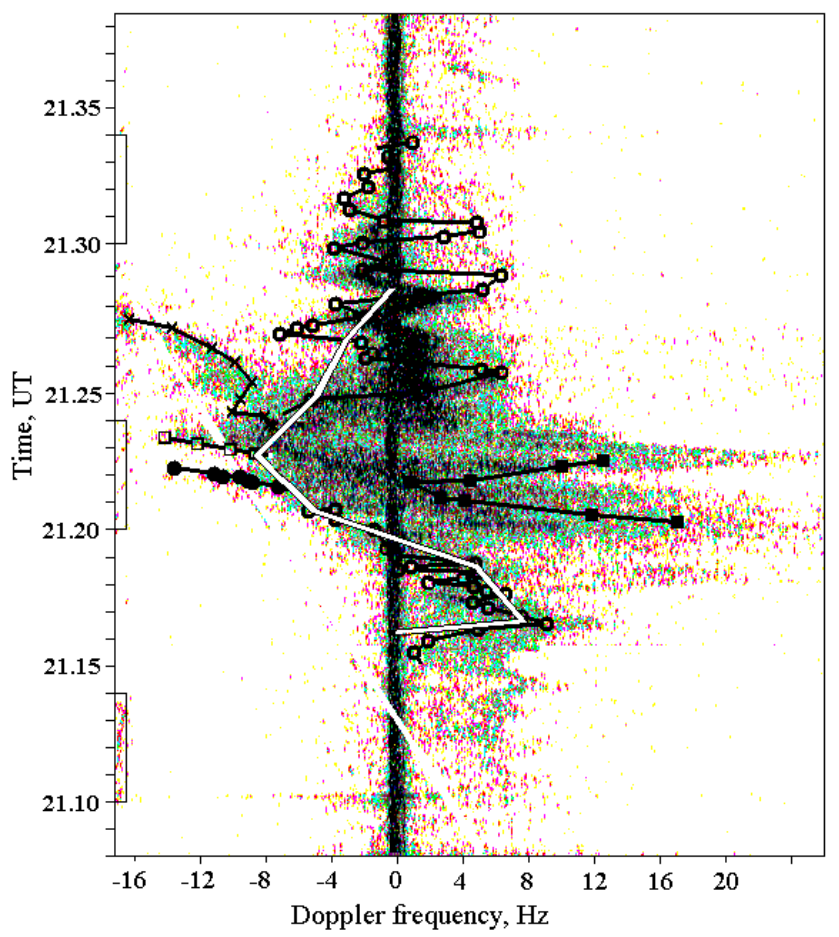

Fig. 9. Comparison between simulation results of Doppler frequency shifts $f_{d}$ and experimental dynamic Doppler spectra at $9410 \mathrm{kHz}$ on the London - Troms $\emptyset$ - St. Petersburg path during the HF pumping experiment on 16 February 1996. The white continuous line shows the calculated values of $f_{d}$ from Fig. $7 \mathrm{c}$; the solid black lines present the calculated values of $f_{d}$ shown in Fig. 8c.

acterize movements in the auroral E-region, which is the region where the diagnostic HF signals are scattered from FAIs. The Doppler frequency shift simulation on the London - Troms $\emptyset$ - St. Petersburg path takes into account not only velocities from the DASI keogram, but also electron density changes in the scattering volume above Troms $\varnothing$ as well (Fig. 2).

\section{Comparison between simulation and observations}

Figure 9 shows the comparison between the simulated Doppler frequency shifts and experimental dynamic Doppler spectra at $9410 \mathrm{kHz}$ on the London - Troms $\varnothing$ - St. Petersburg path during the experiment on 16 February 1996. Doppler frequency shifts calculated on the basis of real velocities obtained from the EISCAT UHF radar (white solid line), as well as from the DASI keogram data (black solid tracks) are overlaid on the experimental observations. Prior to 21:15 UT, there was no similarity between simulated and experimental Doppler frequency shifts (see Figs. 1b, $7 \mathrm{c}$ and $8 \mathrm{c}$ ); hence these simulation data are not shown. Figure 9 shows that the observed and simulated results are in satisfactory agreement from 21:16 to 21:33 UT.

The use of ionospheric plasma velocities from the EISCAT UHF radar at an altitude of $278 \mathrm{~km}$, obtained with $2 \mathrm{~min}$ temporal resolution, replicates on the whole the behaviour of the Doppler frequency shifts of the HF diagnostic wave scattered from FAIs in the E-region, as described by the longlived track (track 1 in Fig. 1b). The best agreement between the simulated and observed $f_{d}$ took place from 21:16 to 21:23 UT. This time interval is characterized by agreement not only in a qualitative sense, but in a quantitative sense as well. Moreover, through that time, the calculated Doppler shifts, taking into account the velocities of FAIs obtained by two different methods, including the EISCAT UHF radar and DASI, correspond closely to one another.

The velocities in the auroral E-region from the DASI keogram with $10 \mathrm{~s}$ resolution adequately describes not only the fine structure of long-lived track 1 , but the tracks with increasing negative values of $f_{d}$ during 21:20-21:22 UT, 21:22-21:23 UT, and 21:24-21:28 UT (tracks 2) as well. Track 2 is in close agreement with the poleward movement of the visible auroral forms (see Fig. 8). However, the very intense wave-like track (track 3) cannot be explained by the DASI velocities. Although the simulated track 3 has wavy $f_{d}$ variations, they are inconsistent with the experimental data of Doppler shifts both in phase and amplitude.

The heater-induced tracks on the Doppler sonogram (tracks 4 and 5) cannot be explained by the CONE model. The burst-like tracks (track 4), appearing when the Troms $\varnothing$ HF heater is turned on or off, may be related to the parametric decay instability. Since the CONE model does not take into account effects produced by the gradients of the HF pump wave electric field, it cannot explain tracks 4. Likewise, heater-induced track 5 also cannot be explained by the CONE model. There are some grounds to believe that the motion of the heater-induced small-scale irregularities in the auroral E-region is not always consistent with the background plasma drift. Supporting evidence includes a similar Troms $\varnothing$ HF pumping experiment carried out on 17 February 1996 in the nightside auroral ionosphere (Blagoveshchenskaya et al., 1998a). During this experiment on the London - Troms $\varnothing$ St. Petersburg path, the pump wave reflected from a sporadic $E_{s}$ layer and well-defined heater-induced Doppler tracks were observed. They were registered only during heater-on periods with small constant Doppler shifts, in spite of the fact that the EISCAT UHF radar observations showed large velocities of the background plasma from 500 to $1000 \mathrm{~m} / \mathrm{s}$ in the north-south direction. This observation provides evidence that the motion of the heater-induced irregularities in the nightside auroral ionosphere is not always the same as the motion of the background plasma.

After 21:30 UT, scattered diagnostic signals on the Doppler sonogram are not observed. A possible reason is that the correct geometry of diagnostic HF radio waves scattered from FAIs in the auroral E-region is no longer valid. This could be due to a lowering of the FAI altitude from 120 to $100 \mathrm{~km}$ that would lead to the absence of scattered signal reception at St. Petersburg. 


\section{Conclusions}

A model for calculations of parameters of HF radio waves scattered from field-aligned small-scale ionospheric irregularities has been developed. It allows for ray tracing, group and phase paths, and Doppler frequency shift calculations. Comparisons between bistatic scatter measurements on the London - Troms $\varnothing$ - St. Petersburg path and simulation results during the Troms $\varnothing$ HF pumping experiment on 16 February 1996 from 21:00 to 22:00 UT are made. Doppler frequency shift $f_{d}$ is calculated on the basis of real velocities obtained from the EISCAT UHF radar measurements at an altitude of $278 \mathrm{~km}$ with 2-min temporal resolution, as well as from the DASI keogram using $10 \mathrm{~s}$ resolution data.

It was found that the observed and simulated results are in satisfactory agreement from 21:16 to 21:33 UT. The best agreement took place from 21:16 to 21:33 UT, when the calculated $f_{d}$, taking into account velocities obtained from the EISCAT UHF radar and DASI keogram, correspond closely to one another. The velocities in the auroral E-region from optical measurements also describes adequately experimental Doppler tracks with increasing negative values of $f_{d}$ associated with the poleward movement of the visible auroral forms.

The developed model cannot explain the heater-induced Doppler tracks. On the one hand, it is induced by the fact that the gradients of the HF pump wave electric field are ignored. On the other hand, it may be suggested that the motion of the heater-induced irregularities in the auroral E-region is not always consistent with the background plasma drift.

It is planned in future to take proper account of the pump wave electric field, the possibility of the excitation of pumpinduced Alfvén waves and other factors.

Acknowledgements. We would like to thank the Director and Staff of the EISCAT. EISCAT is an International Association supported by Finland (SA), France (CNRS), the Federal Republic of Germany (MPG), Japan (NIRP), Norway (NFR), Sweden (NRF), and the United Kingdom (PPARC). Russian authors are grateful to the Russian Foundation of Basic Research, grant N 00-05-64 819. The work of the first two Russian authors was also supported by grants from the Swedish Institute (SI) within the Visby Programme and from Royal Swedish Academy of Sciences (KVA). The second (N. B.) and fourth author (M. R.) were partly supported by NATO Collaborative Linkage Grant, CLG 97 8226. The Swedish author gratefully acknowledges financial support from the Swedish National Sciences Research Council (NFR).

Topical Editor M. Lester thanks C. Hanuise and W. Scales for their help in evaluating this paper.

\section{References}

Anufrieva, T. A. and Shapiro, B. S.: Geometrical parameters of the ionospheric F2-layer, Nauka Press, Moscow, (in Russian), 1976.

Bilitza, D., Rawer, K., Bossy, L., and Gulyaeva, T.: International Reference Ionosphere - Past, Present, and Future: I. Electron Density, Adv. Space Res., 12, 3, 3-13, 1992. .

Blagoveshchenskaya, N. F., Kornienko, V. A., Petlenko, A. V., Brekke, A., and Rietveld, M. T.: Geophysical phenomena during an ionospheric modification experiment at Troms $\varnothing$, Ann. Geophysicae, 16, 1212-1225, 1998a.

Blagoveshchenskaya, N. F., Chernyshev, M. Yu., and Kornienko, V. A.: Excitation of small-scale waves in the F-region of the ionosphere by powerful HF radio waves, J. Atmos. Terr. Phys., 60, 1225-1232, 1998 b.

Blagoveshchenskaya, N. F., Kornienko, V. A., Brekke, A., Rietveld, M. T., Kosch, M. J., Borisova, T. D., and Krylosov, M. V.: Phenomena observed by HF long-distance tools in the HF modified auroral ionosphere during magnetospheric substorm, Radio Sci., 34, 715-724, 1999.

Blagoveshchenskaya, N. F., Kornienko, V. A., Borisova, T. D., Thidé, B., Kosch, M. J., Rietveld, M. T., Mishin, E. V., Luk'yanova, R. Yu., and Troshichev, O. A.: Ionospheric HF pump wave triggering of local auroral activation, J. Geophys. Res., 106, 29 071-29 089, 2001.

Blagoveshchensky, D. V. and Borisova, T. D.: Correction of the HF radio channel model with allowance of the solar and magnetic activity, Geomagn. Aeron., 29, 696-698, (in Russian) 1989.

Brandström, B. U. E., Leyser, T. B., Steen, A., Rietveld, M. T., Gustavsson, B., Aso, T., and Ejiri, M.: Unambiguous evidence of HF pump-enhanced airglow at auroral latitudes, Geophys. Res. Lett., 26, 3561-3564, 1999.

Budden, K. G.: The propagation of Radio Waves, Cambridge Univer. Press, New York, 1985.

Chernyshov, D. V. and Vasil'eva, T. N.: Prediction of the maximal critical frequencies for $\mathrm{W}=10,50,100,150,200$, Nauka Press, Moscow, (in Russian), 1975.

Djuth, F. T., Jost, R. J., Noble, S. T., Gordon, W. E., Stubbe, P., Kopka, H., Nielsen, E., Boström, R., Derblom, H., Hedberg, A., and Thidé, B.: Observations of E-region irregularities generated at auroral latitudes by a high power radio wave, J. Geophys. Res., 90, 12 293-12 306, 1985.

Eglitis, P., Robinson, T. R., Rietveld, M. T., Wright, D. M., and Bond, G. E.: The phase speed of artificial field-aligned irregularities observed by CUTLASS during HF modification of the auroral ionosphere, J. Geophys. Res., 103, 2253-2259, 1998.

Ginzburg, V. L.: The propagation of Electromagnetic Waves in plasma, Nauka Press, Moscow, (in Russian), 1967.

Hanuise, C., Hedberg, A., Orsman, J., Nielsen, E., Stubbe, P., and Kopka, H.: Comparison between the ionospheric plasma drift and the motion of artificially induced irregularities as observed by HF backscatter radars, Ann. Geophysicae, 4, 49-54, 1986.

Haslegrove, J.: Ray Theory and a New Metod for Ray Tracing, Proc. Camb. Conf. Phys. Ionosphere, 355-364, (The Physical Society, London), 1955.

Kosch, M. J., Hagfors, T., and Nielsen, E.: A new digital all-sky imager experiment for optical auroral studies in conjunction with Scandinavian twin auroral radar experiment, Rev. Sci. Instr., 69, 578-584, 1998.

Kravtzov, Yu. A. and Orlov, Yu. I.: Geometric optics of inhomogeneous mediums, Nauka Press, Moscow, (in Russian), 1980.

Noble, S. T., Djuth, F. T., Jost, R. J., Gordon, W. E., Hedberg, A., Thidé, B., Derblom, H., Boström, R., Nielsen, E., Stubbe, P., and Kopka, H.: Multiple frequency radar observations of highlatitude E-region irregularities in the HF modified ionosphere, J. Geophys. Res., 92, 13 613-13 627, 1987.

Rietveld, M. T., Kohl, H., Kopka, H., and Stubbe, P.: Introduction to ionospheric heating at Tromsø., I. Experimental overview, J. Atmos. Terr. Phys., 55, 577-599, 1993.

Rishbeth, H. and vanEyken, T.: EISCAT: Early history and the first ten years of operation, J. Atmos. Terr. Phys., 55, 525-542, 1993. 